\title{
Simulation of Meso-scale Accumulated Damage and Induced Crack Behaviors of CuW Alloy
}

\author{
Wang Yanlong1, $\quad$ Wang Baoe $^{2}, \quad$ Liang Shuhua $^{3}, \quad$ Fu Chong ${ }^{1}$ \\ ${ }^{1}$ Xi'an Polytechnic University, Xi'an 710048, China; ${ }^{2}$ Xizang Minzu University, Xianyang 712082, China; ${ }^{3}$ Xi'an University of Technology, Xi'an \\ 710048, China
}

\begin{abstract}
Considering the relationship between Meso-scale accumulated damage and microstructure, external cyclic strain load was applied on 2D representative volume element (RVE) of $\mathrm{CuW}$ alloys, and the accumulated damage and induced crack behaviors of $\mathrm{CuW}$ alloy were stimulated using Darveaux model. The results show that the plastic slip bands appear on the copper phase at the beginning. Damage and induced cracks of $\mathrm{CuW}$ alloy initiate at the corners and then propagate along the edges of tungsten grains with the increase of cyclic number. The propagation path of micro-cracks is affected by the distribution of tungsten grains mainly, while the sintering necks slow down the propagation speed of micro-cracks to some extent.
\end{abstract}

Key words: $\mathrm{CuW}$ alloy; Meso-scale; accumulated damage; crack

Combining the high electrical and thermal conductivity of copper with the refractoriness and high strength of tungsten, $\mathrm{CuW}$ alloy is widely used as high voltage electrical contacts, welding electrodes, electric discharge machine, and heat sinks ${ }^{[1-3]}$. Under the thermal cyclic load, accumulated damage and induced cracks appear in $\mathrm{CuW}$ alloy and then the service life of the material is reduced.

The accumulated damage process of material can be subdivided into microcosmic and macroscopic phases and the vast majority of service life lies within the microcosmic phase of the damage process in many cases ${ }^{[4,5]}$. Because of the absence of effective test methods on micro-damage observations, the study of damage and induced mic-cracks behaviors were conducted numerically at meso-scale level mostly ${ }^{[6-8]}$. With the numerical prediction, the damage mechanism of materials are clarified and then experimental investigation will be implemented effectively.

Under cyclic load, the fatigue life of materials decrease because of the ratcheting effect induced by the plastic strain accumulation along the mean stress, and the damage processing is mainly controlled by the ratcheting damage caused by the ratcheting deformation ${ }^{[9]}$. Usually, the ratcheting cyclic failure life is predicted by the accumulative damage and the combined energy density ${ }^{[9,10]}$. As we know, the mechanical behaviors of $\mathrm{CuW}$ alloy is affected by its grains features, such as volume fraction and particle distribution ${ }^{[8,11]}$. Applied with different cyclic loads, elastic shakedown, plastic shakedown or plastic ratcheting effect appear on $\mathrm{CuW}$ alloy.

In this study, the meso-scale model was built based on the microstructure of $\mathrm{CuW}$ alloy. The initiation mechanism of accumulated damage and the propagation behaviors of induced cracks for $\mathrm{CuW}$ alloy under cyclic load were investigated with the damage model.

\section{Simulation Model}

\subsection{Darveaux model}

The traditional approach for determining the fatigue life

Received date: June 14, 2016

Foundation item: National High Technique Research and Development Program of China ("863" Program) (2015AA034304); Pivot Innovation Team of Shaanxi Electric Materials and Infiltration Technique (2012KCT-25); National Natural Science Foundation of China (51401154); Special Foundation of Shaanxi Provincial Education Department (14JK1312); Shaanxi Provincial Natural Science Foundation (2015JM5228); Dr. Scientific Research Foundation of Xi'an Polytechnic University (BS13015)

Corresponding author: Liang Shuhua, Ph. D., Professor, School of Materials Science and Engineering, Xi'an University of Technology, Xi'an 710048, P. R. China, Tel: 0086-29-82312181, E-mail: liangsh@xaut.edu.cn 
for a structure is to establish the $S-N$ curves of the materials ${ }^{[12]}$. However, the relationship between the cycle number and the degree of damage or crack length is not clear by the above method. With the hysteresis energy damage theory, Darveaux model is applied to study the relationship between the damage or crack and cyclic number and implemented well by Abaqus software ${ }^{[13]}$. Darveaux model was given as follows ${ }^{[13,14]}$.

$$
N=N_{0}+\frac{D}{\mathrm{~d} D / \mathrm{d} N}
$$

where $N$ is the fatigue life, $N_{0}$ is the cyclic number when damage initiate, and $D$ is the damage degree.

The initiation criterion of damage is characterized by the accumulated inelastic hysteresis energy per cycle $\Delta W$. The cycle number in which damage is initiated is given by

$$
N_{0}=c_{1} \Delta W^{c_{2}}
$$

where $c_{1}$ and $c_{2}$ are the material contacts.

Once the damage initiation criterion is satisfied at some positions of the material, the value of damage is calculated and updated based on the inelastic hysteresis energy for the stabilized cycle. The rate of the damage in a material point per cycle is given by

$$
\frac{\mathrm{d} D}{\mathrm{~d} N}=c_{3} \Delta W^{c_{4}}
$$

where $c_{3}$ and $c_{4}$ are the material constants.

\subsection{Representative volume element (RVE) of CuW alloy}

CuW alloy used in this study was fabricated by infiltrating the pure copper $(99.90 \%)$ into a tungsten skeleton which was activated and sintered by tungsten powder $(4 \sim 6 \mu \mathrm{m})$ and $0.9 \mathrm{wt} \%$ activated sintering element $\mathrm{Ni}$ powder. After annealing $\mathrm{CuW}$ alloy was fabricated, and the microstructure is shown in Fig.1a, in which the dark region is coved with copper phase and the rest is constructed with tungsten skeleton. The nominal mass fraction of tungsten and copper are $70 \%$ and $30 \%$, respectively.

The meso-scale geometry model of $\mathrm{CuW}$ alloys is based on the microstructure of $\mathrm{CuW}$ alloy. Generally, the Meso-model is represented with the representative volume element (RVE) via finite element method (FEM). The Meso-model of $\mathrm{CuW}$ alloy is built by 2D Voronoi diagram which consists of a number of convex polygons. Here, the original set of randomly distributed seeds of Voronoi structures is generated with program Pathon and the needed Voronoi diagrams are constructed with the program Qhull ${ }^{[8,15]}$. Thus, the meso Model of $\mathrm{CuW}$ alloys is achieved by the distinguishing of copper and tungsten phases, as shown in Fig. 1b.

Considering the damage of a material is most likely induced by tensile load under thermal cyclic load ${ }^{[8]}$, cyclic

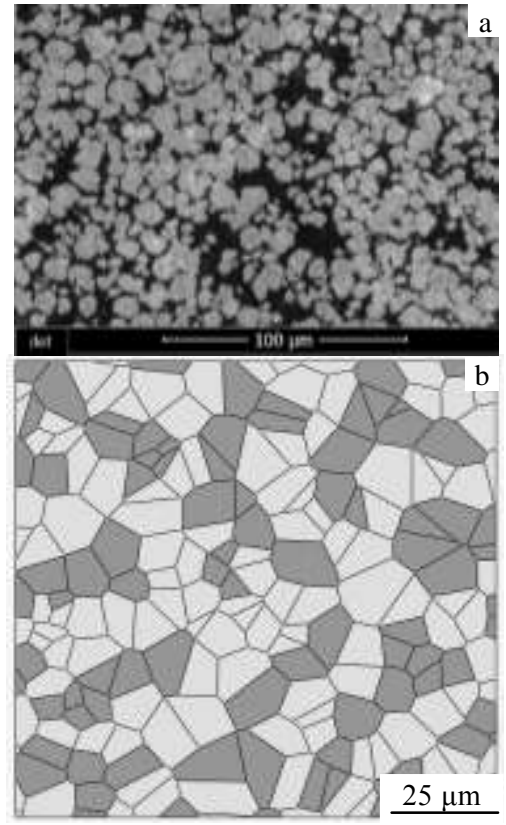

Fig. 1 Microstructure (a) and Meso model (b) of CuW alloys

biaxial tensile strain load with different amplitude was applied on the meso model of $\mathrm{CuW}$ alloy. The finite element analysis was conducted using Abaqus 6.9.

\section{Material Properties}

Though expressed as classic brittle material, as dislocation activity becomes important at high temperatures, the tungsten begins to show ductile behavior, characterized by a marked plastic deformation ${ }^{[16,17]}$, and the elongation rate is $9.5 \%$ at $1505 \mathrm{~K}^{[18]}$. The mechanical properties of the tungsten and copper, such as modulus of elasticity, Poisson's ratio, and yield strength are listed in Table 1.

The low cycle fatigue behaviors and related parameters of tungsten studied rarely were given by R. E. Schmunk et al. at $1088 \mathrm{~K}^{[20]}$, and the constants of $c_{1}, c_{2}, c_{3}$ and $c_{4}$ of tungsten were calculated using the trust region algorithm in MATLAB software under the confidence of $95 \%$, as listed in Table 2.

\section{Results and Discussion}

\begin{tabular}{|c|c|c|c|c|}
\hline Material & $\begin{array}{c}\text { Young's } \\
\text { modulus/GPa }\end{array}$ & $\begin{array}{c}\text { Poisson } \\
\text { Ratio }\end{array}$ & $\begin{array}{c}\text { Yield Strength/ } \\
\mathrm{MPa}\end{array}$ & $\begin{array}{c}\text { Ultimate } \\
\text { Strength/MPa }\end{array}$ \\
\hline Tungsten & $378^{[19]}$ & 0.28 & $411^{[20]}$ & $428^{[20]}$ \\
\hline Copper ${ }^{a}$ & 110 & 0.345 & 57 & 219.2 \\
\hline
\end{tabular}

\subsection{Initiation of accumulated damage}

Table 1 Mechanical properties of tungsten and copper

Note: a-from pure copper tension experiment 
Table 2 Material constants of Darveaux model for $\mathrm{Cu}$ and $\mathrm{W}$

\begin{tabular}{ccccc}
\hline \multirow{2}{*}{ Material } & $c_{1}$ & $c_{2}$ & $c_{3}$ & $c_{4}$ \\
\cline { 3 - 5 } & $($ cycle/MPa $)$ & & $\mathrm{mm} \cdot(\mathrm{cycle} / \mathrm{MPa})^{-1}$ & \\
\hline Tungsten & 13.58 & -1.281 & 1.809 & 1.899 \\
Copper $^{[14]}$ & 41.2 & -1.433 & 0.0037 & 1.768 \\
\hline
\end{tabular}

When the value of amplitude of cyclic load is relatively low, only elastic deformation without damage appears on $\mathrm{CuW}$ alloy. With the increase of strain load, damage initiates and then cracks occur after the certain cyclic number. The strain energy for RVE under $0.15 \%$ strain load is shown in Fig.2, damage is not activated and material is shakedown before the twelfth cycle load. The strain energy decreases gradually after the 13th load and then declines from the 53rd cycle load which means that damage occurs and increases obviously in $\mathrm{CuW}$ alloy. After the 78th cycle, strain energy is only about one fifth of original value.

Though no damage appear before 13th cycle load, plastic deformation occurs at the beginning of fatigue process, as shown in Fig. 3. The plastic shear slip bands are found after the first cycle even at the corner and connection of copper phase, and only elastic deformation takes place on the tungsten skeleton on the whole (Fig. 3a). This is because copper phase has smaller yield strength than tungsten, and hence is more easily prone to plastic deformation. Shear bands appear on copper phase but can not reach the fracture limit for its better ductile. With the increase of cyclic number, local plastic deformation enhance, as shown in Fig. $3 b$, dislocations are piled up for the plastic deformation and triggered stress concentration at the edges and corners of copper phase.

With the increase of strain load, micro-crack initiates because of the ratcheting effect in $\mathrm{CuW}$ alloy under $0.15 \%$ strain load. As shown in Fig. $4 \mathrm{a}$ and $4 \mathrm{~b}$, the nucleation of damage occurs near the corner of tungsten grain firstly in which stress concentration takes place usually, and then grows up with the increase of cycle number. The crack induced by damage appears when the value of damage is 1 ,

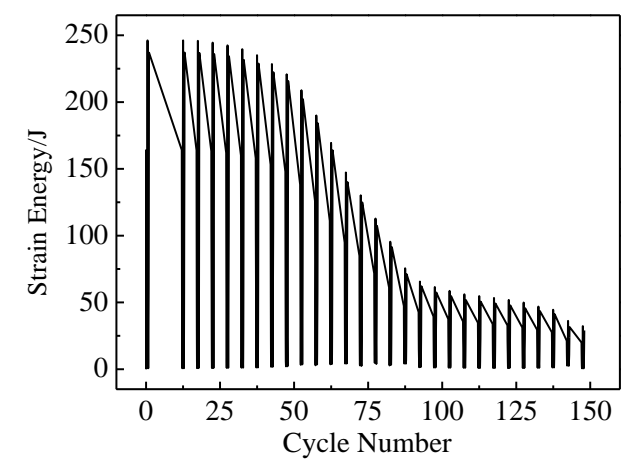

Fig. 2 Variation of strain energy for RVE

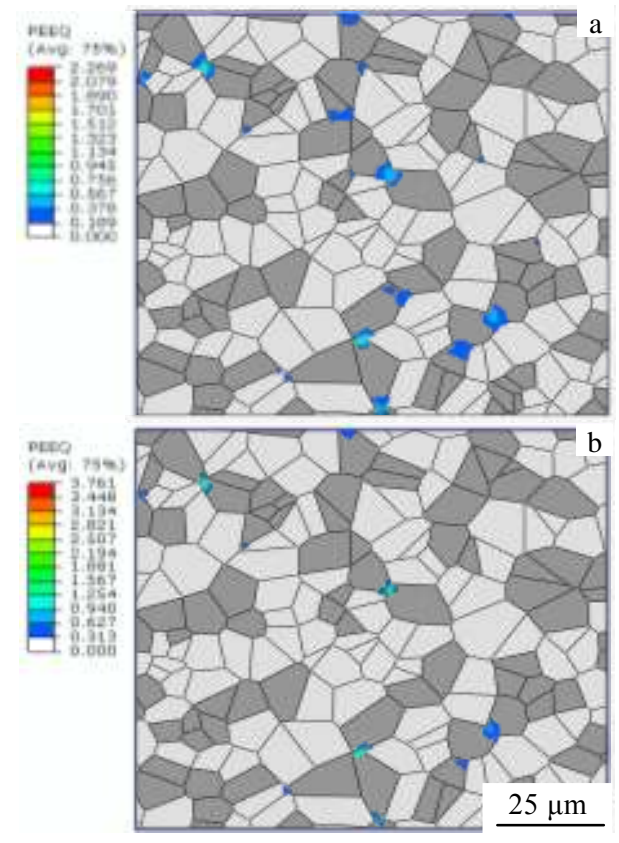

Fig. 3 Equivalent plastic strain of RVE: (a) after the first cycle and (b) after the 13th cycle
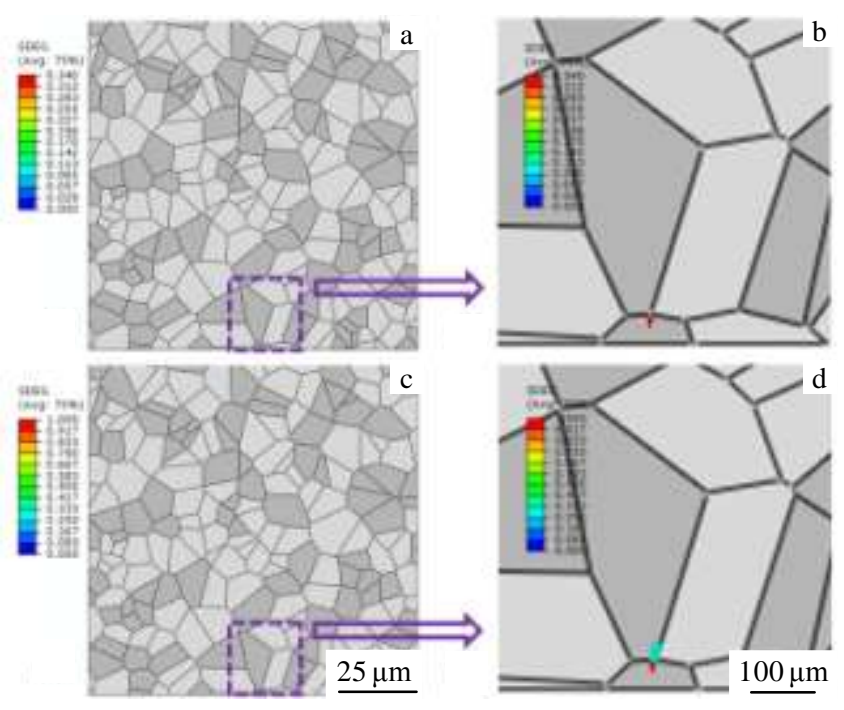

Fig. 4 Nucleation of damage and induced micro-crack after the 13 th cycle $(a, b)$ and after the 18 th cycle $(c, d)$

and new damage appears next to induced crack toward copper phase along the edge of tungsten grain, as shown in Fig. $4 \mathrm{c}$ and $4 \mathrm{~d}$. Therefore, rounded tungsten skeleton is accepted more with the addition of some elements or sintering at higher temperature in order to reduce the sensitivity to cracking ${ }^{[21]}$.

\subsection{Micro-cracks behavior under cyclic strain load}

The micro-cracks behaviors of $\mathrm{CuW}$ alloy under $0.15 \%$ strain load are shown in Fig.5. After the 38th cycle load, 


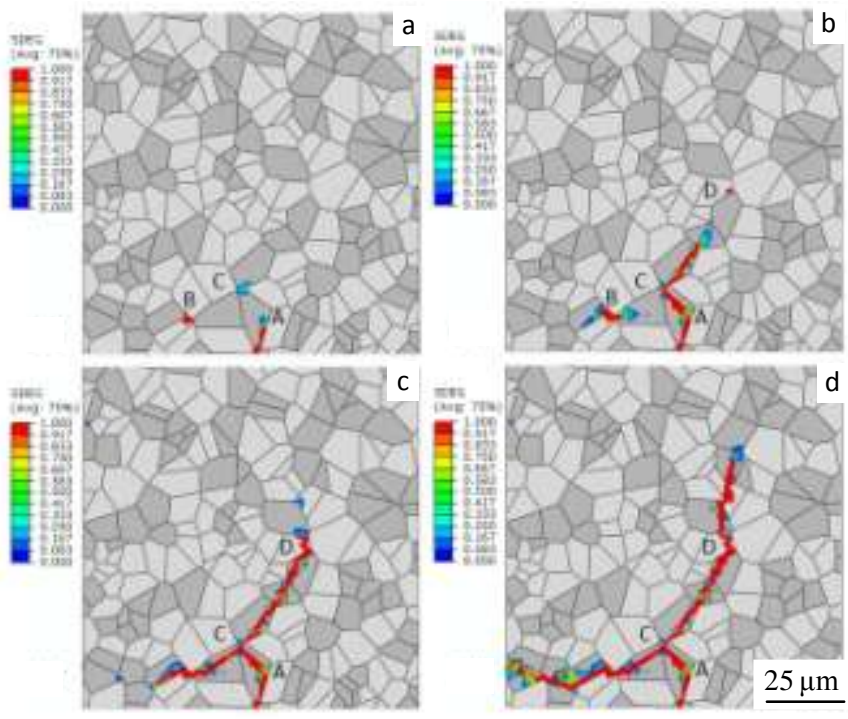

Fig. 5 Distribution of damage and micro-crack behavior under cyclic strain load of $0.15 \%$ : (a) after the 38 th cycle, (b) after the 58th cycle, (c) after the 68th cycle, and (d) after the 88th cycle

cracks propagate along the $\mathrm{W} / \mathrm{Cu}$ interface because of the mismatch of mechanical properties, and then toward the corner of tungsten grain (point A) for the stress concentration, while new crack take place in sintering neck at point $\mathrm{B}$ and damage occur obviously at point $\mathrm{C}$, as shown in Fig. 5a. With the increase of cycle number, plastic deformation accumulates, cracks propagate continually and then coalesce at point $\mathrm{C}$. Then, cracks propagate into the $\mathrm{Cu}$ phase, tend to the boundary of $\mathrm{W}$ grains and then pass through the sintering neck (point $\mathrm{D}$ ) to the other $\mathrm{Cu}$ phase. The crack path depends on the distribution of copper and tungsten phase, and propagates perpendicular or incline along $45^{\circ}$ to the direction of strain load which means the driving force of crack propagation is transforming between maximum tensile stress and shear stress, as shown in Fig. 5c and Fig. 5d. As the main crack form, no damage appear obviously beside the main crack path and the carrying ability of $\mathrm{CuW}$ alloy is reduced significantly.

The damage of RVE of $\mathrm{CuW}$ alloy under transient arcing are dominated by tensile load induced with high temperature gradient mainly ${ }^{[8]}$. The internal microstructure of $\mathrm{CuW}$ alloy after repeatedly high voltage arcing is shown in Fig. $6^{[21]}$. The main crack propagates through the sintering neck $A$ and continues into copper phase, the path of crack tend to the boundary of tungsten grains and then bypasses the corner of the other tungsten grain $\mathrm{B}$. The behavior of cracks matches well with the results of above simulation.

The micro-crack length variation with the number of load cycle is shown in Fig. 7. Cracks appear and then propagate gradually before the 48th cycle when sintering neck is

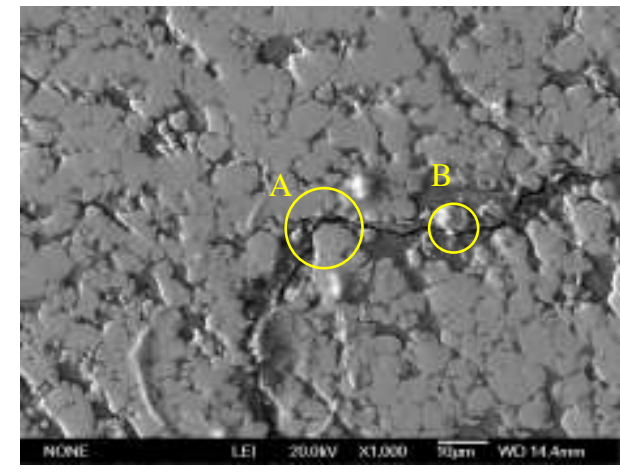

Fig. 6 Internal crack of $\mathrm{CuW}$ alloy after repeatedly high voltage $\operatorname{arcing}^{[21]}$

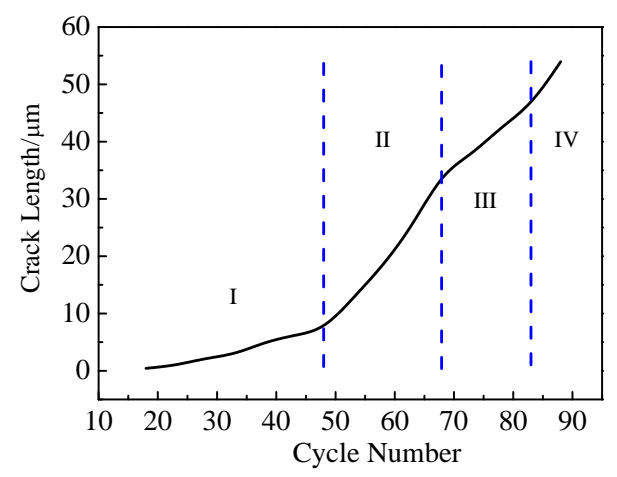

Fig.7 Micro-crack length variation with the number of cycle

disconnected, cracks coalesce and direction changes. The crack propagates faster in the rich copper region than before, and then slows down when it arrives the new sintering neck of tungsten for its higher strength compared with copper phase after the 68th cycle. When the sintering neck is fractured, the propagation velocity increases again after the 83th cycle. Therefore, the crack propagation is delayed by the sintering neck of tungsten, and the orient changing of crack propagation will slow the propagation velocity a little.

\section{Conclusions}

1) The $2 \mathrm{D}$ meso-scale model of $\mathrm{CuW}$ alloys was developed with Voronoi technique, and $\mathrm{FE}$ analysis is performed on the representative volume element of $\mathrm{CuW}$ alloys with Darveaux model to reveal the mechanism of the accumulated damage and induced cracks of $\mathrm{CuW}$ alloy.

2) Plastic slip bands appear in the copper phase at the beginning of fatigue process. Accumulated damage and induced cracks of $\mathrm{CuW}$ alloy initiate near the corners of tungsten grains, and then propagate along the edges of tungsten grains or across the sintering necks with the increase of the cyclic number. 
3) The main paths of cracks are formed by the direction of strain load and the distribution of edges and corners for tungsten grains mainly. The cracks propagate directly through the rich copper region of $\mathrm{CuW}$ alloy, and then slow down when passing through the sintering necks.

\section{References}

1 Vettivel S C, Selvakumar N, Narayanasamy R et al. Materials \& Design[J], 2013, 50: 977

2 Yang X H, Liang S H, Wang X H et al. International Journal of Refractory Metals \& Hard Materials[J], 2010, 28: 305

3 Ho P W, Li Q F, Fuh J Y H. Materials Science \& Engineering $A[\mathrm{~J}], 2008,485: 657$

4 Künkler B, Krupp U, Christ H J et al. International Journal of Fatigue [J], 2006, 28: 983

5 Tokaji K, Takafuji S, Ohya K et al. Journal of Materials Science[J], 2003, 38: 1153

6 Grassl P, Rempling R. Engineering Fracture Mechanics[J], 2008, 75: 4804

7 Ghosh R, De S. Mechanics of Materials[J], 2014, 68: 147

8 Wang $\mathrm{Y}$ L, Liang S H, Ren J T. Materials Science \& Engineering $A[\mathrm{~J}], 2012,534: 542$

9 Korthäuer M, Ataya S, Salem A et al. Computational Materials Science[J], 2007, 39: 219

10 Wang Y L, Liang S H, Xiao P et al. Computational Materials
Science $[\mathrm{J}], 2011,50: 3450$

11 Huang Y T, Ping T D, Zhe C W. Transactions of Materials and Heat Treatment $[\mathrm{J}], 2005,27: 1124$ (in Chinese)

12 Acevedo C, Nussbaumer A. International Journal of Fatigue [J], 2012, 36: 171

13 Abaqus Analysis User's Manual Version 6.9[M]. Providence, RI, USA: Dassault Systèmes Simulia Corp, 2011

14 Qu X, Chen Z Y, Qi B et al. Microelectronics Reliability[J], 2007, 47: 2197

15 Barber C B, Dobkin D P, Huhdanpaa H T. ACM Trans Math Software [J], 1996, 22: 469

16 Rupp D, Weygand S M. Journal of Nuclear Materials[J], 2009, 386: 591

17 Giannattasio A, Tanaka M, Joseph T D et al. Physica Scripta [J], 2007, T128: 87

18 Schmunk R E, Korth G E, Ulrickson M. Journal of Nuclear Materials[J], 1984, 122: 850

19 Hirai T, Pintsuk G. Fusion Engineering \& Design[J], 2007, 82: 389

20 Schmunk R E, Korth G E. Journal of Nuclear Materials[J], 1981, 104: 943

21 Zhang Q, Yang X H, Liu B Y et al. High Voltage Apparatus[J], 2016, 52: 27 (in Chinese)

\title{
$\mathrm{CuW}$ 合金的细观累计损伤及裂纹演变模拟分析
}

\author{
王彦龙 ${ }^{1}$, 王宝娥 ${ }^{2}$, 梁淑华 ${ }^{3}$, 付 羽 $^{1}$ \\ (1. 西安工程大学, 陕西 西安 710048) \\ (2. 西藏民族大学, 陕西 咸阳 712082) \\ (3. 西安理工大学, 陕西 西安 710048)
}

\begin{abstract}
摘 要: 考虑到细观 (Meso-scale) 累计损伤与微观结构的相互关系, 对CuW合金的二维代表体单元施加循环载荷, 应用Darveaux模型分 析了 $\mathrm{CuW}$ 合金的累计损伤以及所引起的裂纹演变。分析结果表明：塑性滑移带首先形成于 $\mathrm{CuW}$ 合金的铜相区, 随着循环次数的增加, 细观损伤及裂纹萌生于铇颗粒的棱角处并沿着其边缘扩展, 微裂纹的扩展路径主要受铇颗粒的分布状况影响, 而烧结颈在一定程度上迟 滞了微裂纹的扩展速度。
\end{abstract}

关键词: CuW 合金; 细观 (Meso-scale); 累计损伤; 裂纹

作者简介: 王彦龙, 男, 1974 年生, 博士, 讲师, 西安工程大学机电工程学院, 陕西 西安 710048, 电话: 029-82312185, E-mail: yanlongw@126.com 